\title{
Evaluating the Self-Expressed Unmet Needs \\ of Emancipated Foster Youth Over Time
}

\begin{abstract}
This study explores the self-reported unmet need for independent living services of young people making the transition to adulthood from foster care after the creation of the Chafee Foster Care Independence Program. We find that $34.5 \%$ of youth indicated they had an independent living service need that went unmet at age $17,27.9 \%$ at age 21 and $35.5 \%$ at age 23 , with the largest percentage indicating they lacked preparation in the area of finance. Some of these youth expressed unmet need consistently while others' expression of unmet need fluctuated over time. Youth who indicated that they had mental health issues were significantly more likely to report unmet need at baseline and wave 3. Youth who indicated that they received more social support and independent living services were less likely to report unmet need at baseline and wave 3 . These youth perspectives could lead to the enhancement of existing independent living skills provision as states prepare to extend the age of foster care benefits, ultimately making them more timely and effective.
\end{abstract}

\section{Keywords}

Foster youth; emancipation; unmet needs; child welfare policy 


\section{Introduction}

The transition to adulthood is a sudden one for youth who age-out of the foster care system. Upon turning 18 years old (or, in some states, 21 years old), foster youth become emancipated from the guardianship of the state with the expectation that they will be able to effectively provide for themselves as independent adults. While young adults outside of the foster care system can lean on their parents for support in areas such as finance and housing, foster youth tend to enter independent life without prerequisite skills in these areas, without knowledge of resources available to them, and without familial support. It's no surprise that these teenagers and young adults have historically found themselves in great need; their struggles have been widely documented in the literature (see, e.g., Courtney, 2009; Courtney, Dworsky, Brown, Cary, Love \& Vorhies, 2011; Courtney, Terao \& Bost, 2004; Berzin, Rhodes \& Curtis, 2011; Havlicek, 2011; Mares, 2010; Pecora et al, 2003).

In an attempt to ameliorate this need, the Federal Government established the Independent Living Program in 1986 as an amendment to Title IV-E of the Social Security Act. Funding was given to states with the expectation that they would establish programs to help prepare teens and young adults for the transition to independent life. Further federal support was given in 1999 when the Foster Care Independence Act authorized the creation of the John Chafee Foster Care Independence Program. This resulted in the doubling of amount of money available to states and gave states greater discretion in spending. The Chafee Program also granted states the option of extending independent living services (and Medicaid coverage) until youth turned 21. The need for continuing support after age 18 has since been reaffirmed; with the passage of the Fostering Connections to Success and Increasing Adoptions Act in 2008, Title IV-E was amended to include federal reimbursement for costs of foster care payments at state option until 
qualifying youth are 21 years of age. This reimbursement became available beginning in the federal fiscal year of 2011 .

As a result of these advances, many youth who are aging out of foster care receive some form of independent living services prior to emancipation, however the types of services differ significantly by state (Dworsky \& Havlicek, 2009; USGAO, 2004). Some agencies offer teenspecific foster care programs, aimed specifically to target the needs of older foster youth and prepare them for independent living. However, despite the focus on this issue in child welfare policy over the past twenty-five years, teens continue to report that they have trouble transitioning to adulthood. The study reported here explores the self-reported unmet need for services of young people making the transition to adulthood from foster care after the creation of the Chafee Program. Specifically, it examines the level and nature of unmet need, trends in unmet need between age 17 and 21, the relationship between expressed unmet need and various youth characteristics, and whether youth who report receiving more independent living preparation are less likely to report having needs that went unmet by their agency. Before describing the study and its findings, we turn to a review of relevant prior research.

\section{Background}

There have been a handful of small qualitative studies done to examine the troubles that older youth in foster care and those making the transition to adulthood face and their needs that continue to go unmet. While these studies have only interviewed small groups of young adults who have become emancipated, the needs they have expressed have emerged somewhat thematically. 
Youth who were interviewed have expressed concern about the provision of effective case management services (Mares, 2010; Geenen \& Powers, 2007; Iglehart \& Becerra, 2002; Scannapieco et al, 2007; McMillen et al, 1997; Barth, 1990). These youth tend to feel as though foster care case management services are disorganized and impersonal (Geenen \& Powers, 2007; Scannapieco et al, 2007; Mares, 2010), providing little benefit in the preparation for independent life. They alternatively suggested that the ideal caseworker/client relationship has the potential to protect against various risks associated with aging out, and provide them with critical support and knowledge. Geenen and Powers (2007) found that the youth they interviewed called for a single, long-standing case management relationship with a worker who crafted an individualized transition plan to meet their unique needs. The need for individualized transition planning was echoed in a similar study conducted by Scannapieco and colleagues (2007). The teens in this study hoped that a personal relationship with their caseworker would allow for greater inclusion of their perspective and wishes in transition planning. They conceived of optimal case management as an ongoing, cooperative, creative endeavor, as opposed to a one-size-fits-all agency requirement.

Youth tended to have more success in developing mentor-like relationships and securing useful services in the context of independent living programs (ILP). McMillen et al (1997) found that ILP classes were places where youth could come together and form relationships with each other and with group facilitators. Mares (2010) found that the youth he interviewed were generally interested in the content delivered in independent living classes, and that they also tended to enjoy the opportunity to connect with other emancipating youth. Youth in a different study (Iglehart \& Becerra, 2002) found similar benefits, but expressed that they believed these ILP classes should happen closer to the time of their transition out of foster care (as opposed to 
years prior). Further, the youth interviewed in the Iglehart \& Becerra study all identified as people of color; they called for the involvement of former foster youth of color and suggested they play a formalized peer educator role in the ILS curriculum.

Independent Living Programs tend to offer trainings in a variety of areas, however some appear to be more relevant than others. Teens have reported that there is a particular need for financial skill instruction, particularly in the area of money management i.e. budgeting, using a checkbook, comparison-shopping, building credit and financial goal setting (Mares, 2010; Barth, 1990; McMillen et al, 1997; Scannapieco et al, 2007). There was also a focus on the importance of developing skills in the process of locating and transitioning to independent housing (McMillen at al, 1997; Barth, 1990). Training on topics such as birth control and cooking were seen as useful (McMillen et al, 1997). There also appeared to be an interest in and need for training in the area of locating useful community resources and programs (McMillen et al, 1997; Scannapieco et al, 2007).

While the acquisition of these hard skills is important to success, teens also call for a focus on the development of soft skills that focus on self and interpersonal awareness. Youth expressed a need for support groups and independent psychotherapeutic treatment to help them cope with the transition to independent living (Scannapieco et al, 2007). They are also interested in personal relationship development and preservation (Iglehart \& Becerra, 2002). They tend to believe that caseworkers or counselors may be people with whom they may be able to develop long-term mentoring relationships, and from whom they could learn these soft skills.

Foster parents were also identified by these teens as potential mentors and informal trainers. Foster youth have often developed strong, long-standing relationships with their foster parents (Barth, 1990) and feel as though these parents would be the most appropriate source of 
training and support for independent living (Mares, 2010; McMillen et al, 1997; Geenen \& Powers, 2007; Scannapieco et al, 2007). Foster homes are an ideal setting for both hard and soft skills training because there are likely many daily opportunities for foster youth to see how foster parents manage their finances, tend to their households, and participate in relationships with their friends and family members.

When considering the perspectives of foster youth and the professionals that serve them regarding the characteristics of potentially effective independent living services, it is important to keep in mind that extant evaluation research has found very limited evidence of the effectiveness of these services (Montgomery, Donkoh \& Underhill, 2006; Courtney, Zinn, Johnson, \& Malm, 2011; Courtney et al, 2008) or how often these services are, in fact, offered at all. Courtney, Lee \& Perez (2011) using data from the current study $(\mathrm{n}=732)$ demonstrate that most youth who are aging-out of foster care are receiving far fewer services than they qualify for under the Chafee Act. At ages 17 and 18, they report receiving approximately $30 \%$ of the services to which this federal legislation states they are entitled. Further, there are significant differences in experiences and demographic characteristics of those who report receiving more services: (1) those who report receiving more services before age 17 or 18 are likely to continue to report receiving services at later ages; (2) after age 17, youth who remain in care longer are more likely to report receiving independent living services than those who leave earlier; (3) those who are in group care shortly before emancipation are more likely to receive independent living services than their counterparts in family foster care, especially in the area of employment, which may be a result of the contractual obligation group care staff have to provide said services; (4) African Americans were more likely to receive education-related skills than their white counterparts and (5) males 
tend to report getting fewer services than their female counterparts, which may be due to their higher levels of incarceration.

Nevertheless, as states prepare to extend the age of foster care benefits, the consideration of youths' perspectives could lead to the enhancement of existing independent living services, ultimately making them more timely and effective.

\section{Research Questions}

Findings of prior research provide an important, albeit incomplete, picture of the independent living skills acquisition of youth aging out of the foster care system. In particular, the majority of existing studies rely on small convenience samples, contributing to questionable generalizability of their findings, despite their general consistency. It is unclear whether these same observations would emerge in a much larger and more representative sample. Moreover, it remains unclear how perceptions of need would change over time as youth encounter different challenges associated with independent living, since prior research has examined need at a point in time. It is also unclear whether or not these trends would vary in accordance with certain youth characteristics and experiences. The identification of these previously unexplored areas of scholarship contributed to the following four research questions:

1. What percentage of youth making the transition to adulthood from foster care identify unmet needs in their preparation for independent living? In what domains do perceived unmet needs fall? 
2. To what extent do expressed needs change over time? Do youth who initially express no unmet need come up against unforeseen challenges as they age that lead them to conclude that they do, in fact, have needs that were unmet by their child welfare agency?

3. Is there a relationship between expressed need and various youth characteristics?

4. Are youth who report receiving more independent living preparation significantly less likely to report having needs that went unmet by their agency?

\section{Research Design \& Methods: The Midwest Study}

The Midwest Evaluation of the Adult Functioning of Former Foster Youth ('The Midwest Study') is a longitudinal study that has followed youth in the states of Illinois, Iowa and Wisconsin as they 'age out' of the child welfare system and transition to adulthood. The Midwest Study is unique in being the only large-scale longitudinal examination of the transition to adulthood for foster youth who came of age after the passage of the Foster Care Independence Act of 1999. The three states involved in the study have both urban and rural out-of-home care populations and differ in respect to their policies regarding when the state ceases to have legal responsibility for the care of foster youth. The Midwest Study involves five waves of survey data collection, however in this paper we will be focusing specifically on waves 1 through 3 . When conducting interviews at each wave, a professional interviewer typed subject responses into a data field. The interviews were all conducted in person except when the subject had moved out of state (in that case, interviews were conducted by phone).

Baseline survey data were collected between May 2002 and March 2003 from 732 youth who were 17 or 18 years old and still under the jurisdiction of the state child welfare agency. All of the youth had entered care before their 16th birthday and were still in out-of-home care on 
their 17th birthday. The primary reason for their placement was neglect and/or abuse. All but 34 of the 732 were still state wards at the time of the baseline interview, the others having left care between selection of the sample and the baseline interview. Wave 2 survey data were collected between March and December of 2004 from 603 youth who were 19 or 20 years old (this was eighty two percent of the baseline sample). Wave 3 survey data were collected between March 2006 and January 2007 from 591 youth who were 21 or 22 years old (this was eighty one percent of the baseline sample). There were 513 youths who participated in the baseline interview $(\mathrm{n}=$ $732)$, wave 2 interview $(n=603)$ and wave 3 interview $(n=602)$, or 70 percent of the total baseline sample.

Iowa and Wisconsin are like most states in that foster youth typically "age out" when they are 18 years old. Illinois is one of the few states in which young people can (and routinely do) remain in care until age 21. Consequently, when the second wave of data was collected, 282 of the young people who were interviewed were still in foster care, and all but two of those young people were from Illinois. In fact, $72 \%$ of the Illinois youth were still in care when they were interviewed at age 19 . None of the youth in the study were still in care when the third wave of data was collected.

The baseline interview focused on the experiences of the youth while in care and covered a variety of domains including education, employment, physical and mental health, social support, relationships with family, delinquency and contact with the criminal justice system, victimization, substance abuse, sexual behavior, and receipt of independent living services (Courtney et al, 2004). The second interview covered many of the same domains as the first, but it focused on the young adults' experiences since the first interview and, in the case of discharged young adults, included questions about their lives after leaving care. The third interview similarly covered the 
previously mentioned domains and focused on the experience of the young adult since the second interview.

\subsection{Measures}

The dependent variable of interest here is the youths' perception of unmet need for independent living services. At each wave, youth were asked about a variety of forms of help they had received in preparation for independent living in survey form. Specifically, youth were asked about "training you may have received to help you be ready to live on your own" during all three surveys. At baseline, there was no specification as to who provided the training. At waves 2 and 3, youth were asked about trainings they received from the child welfare agency since their last interview. ${ }^{1}$ We refer to these forms of help as "independent living services," though it is worth noting that the questions capture self report of receiving particular kinds of help, not a particular service per se. At each survey wave, after completing this series of questions, they were asked the following question: "Is there any training or assistance that you were not given, that you wish your agency had given you to help you learn to live on your own?" If they answered this question affirmatively, they were then asked by the interviewer to describe these unmet needs.

The qualitative responses to this open-ended question were recorded, transcribed and coded separately by two masters-level coders. Coders organized these data into the following domains: finance, housing, health, education, employment, life skills, relationships and "all of the above." Coders were trained how to code for each domain. Each coder read 30 cases separately then

\footnotetext{
${ }^{1}$ The wording of the questions about receipt of independent living services was changed after the baseline survey because the participating states were particularly interested in whether youths were receiving services through the child welfare agency after reaching the age of majority. Thus, the baseline responses can be seen as youths' reports of all kinds of help they received prior to age 17-18, whereas the responses at waves 2 and 3 pertain to help that they report receiving through their agency between interview waves.
} 
regrouped to discuss their methods of coding before continuing on to the remaining cases at each wave. By coding a response to indicate one of these domains, the coder believed that the respondent clearly indicated that they had an unmet need in that area and inadequate independent living preparation relating to the skills relevant to that domain. Coders used the code "all of the above" when a respondent indicated that they had unmet needs in all of our defined domains. Some responses were coded for more than one domain.

Kappa tests were run to determine interrater reliability (IR) between the two coders. IR was consistently high in the domains of finance, housing, health, education, employment and “all". At baseline, it ranged between $80 \%$ and $97 \%$; at wave 2, it ranged between $76 \%$ and $96 \%$ and at wave 3 it ranged between $75 \%$ and $91 \%$. However, IR was moderate for the domain of "relationships" (58\% at baseline, $34 \%$ at wave 2 and $32 \%$ at wave 3$)$. It was poor to slight for the life skills domain (39\% at baseline, $-.9 \%$ at wave 2 and $22 \%$ at wave 3 ). The very poor IR for life skills and the fact that very few youth indicated an unmet need in this area across three waves (n $=61,8.3 \%$ ) led us to exclude the life skill domain from further analyses. We chose to specifically examine the relationship between expressed unmet need and the following measures: (1) demographic characteristics (race, gender and state); (2) measures of youth functioning (mental health, substance abuse, delinquent behavior, education, and employment); (3) perceived social support; (4) placement characteristics (instability over time, placement type at baseline, and length of time in care after age 18); and (5) self-reported receipt of independent living services. See Tables 1 and 2 for descriptive statistics on these variables.

\subsubsection{Demographic Characteristics}


We are not aware of prior research that has sought to identify differences between racial groups, sexes or child welfare jurisdictions in the expression of unmet need and we had no hypotheses concerning the relationship between these factors and perceptions of unmet need. However, Courtney, Lee and Perez (2011) found a number of important differences in their study on the receipt of independent living services, which may be related to the expression of unmet needs. Since state is strongly associated with race in the Midwest Study states (e.g., the majority of youth in Illinois were African American, but that is not the case in Iowa or Wisconsin), we needed to control for state in order to assess relationships between race and unmet needs without the potentially confounding effect of differences between states in service availability. Courtney, Lee \& Perez (2011) found that African American youths were more likely to receive educationrelated independent living services, controlling for state. Courtney, Lee and Perez (2011) also found that females were more likely to receive independent living services in the areas of health and general education than males. For the logistic regression model predicting unmet service need at baseline, youth from each state remained separate. For the logistic regression model predicting unmet service need at wave 3, youth from Iowa and Wisconsin were aggregated into one group and youth from Illinois remained separate, reflecting the policy difference between Illinois, which allowed youth to remain in care to age 21 at the time of the study, and Iowa and Wisconsin, which did not.

\subsubsection{Youth Functioning}

We hypothesized that youth with challenges in selected areas of functioning would be more likely to perceive unmet need for services intended to help them prepare for independent living. The Composite International Diagnostic Interview (CIDI; World Health Organization, 
1998) was used to collect information on mental health and substance abuse symptoms for these youth. Our interest was in the degree to which symptoms might influence the extent to which youth perceived a need for independent living services. Rather than establishing a formal diagnosis, we created variables based on the presence of symptoms. For the logistic regression model predicting unmet service need at baseline, all youth who reported having experienced five or more depressive symptoms or one or more symptoms of posttraumatic stress (the most common problems reported) since age 16 were coded as having a mental health problem. All youth who reported experiencing one or more symptoms of drug or alcohol dependency or abuse were coded as having a problem with substance use. For the logistic regression model of unmet need at wave 3, similar measures were constructed based on symptoms experienced during the year prior to the wave 3 interview.

To capture externalizing behavior problems we used survey items from the National Study of Adolescent Health (Udry, 2003) that measured delinquency. At baseline, we used a cumulative measure of seven items referencing youth behaviors over the prior 12 months: (1) deliberately damaged someone else's property; (2) stole something worth more than $\$ 50$; (3) entered a house or building to steal something; (4) used or threatened to use a weapon to get something from someone; (5) sold marijuana or other drugs; (6) stole something worth less than $\$ 50 ;(7)$ took part in a fight where a group of friends was against another group (alpha $=.70)$. Item means were used when subjects did not answer one of these questions. At wave 3, we used a cumulative measure of six items referencing youth behaviors over the prior twelve months: (1) deliberately damaged someone else's property; (2) stole something worth more than $\$ 50$; (3) entered a house or building to steal something; (4) used or threatened to use a weapon to get something from someone; (5) stole something worth less than $\$ 50$; (6) hurt someone badly 
enough that they needed medical care $($ alpha $=.50)$. These questions were selected because they were more slightly appropriate for youth around 21 years of age than those asked at baseline. Item means were used when subjects did not answer one of these questions.

Our measures of educational attainment vary between the baseline and wave 3 logistic regression models reflecting the overall increase in attainment over time. For the baseline model we include an indicator of whether the youth has been retained at least one grade in school. For the wave 3 analysis we created a variable that includes three ordered categories of educational attainment: no high school diploma or General Equivalency Degree (GED); high school diploma or GED but no college; at least some college. For the baseline logistic regression model of unmet need we included an indicator of whether or not the youth reported ever working prior to baseline. For the wave 3 logistic regression model of unmet need we included an indicator of whether the youth reported being currently employed.

\subsubsection{Social Support}

Youth who are aging out of foster care may look to those to whom they feel closest for the acquisition of independent living skills. For this reason we chose to examine the relationship between expressed unmet need and expressed social support, hypothesizing that those youth who reported having more social support would be less likely to report unmet need.

We created measures of social support from the baseline and wave 3 interviews by summing the extent to which the youth felt that they had (1) enough people to talk to; (2) enough people to ask favors of; (3) enough people from whom they could ask for money and (4) enough people to encourage them. Social support items were reverse coded and summed to form a measure of perceived social support $($ alpha $=.75)$. 


\section{$\underline{\text { 4.1.4 Placement Characteristics }}$}

We included measures of placement experiences prior to baseline in our logistic regression model of unmet need at baseline. Our interest in examining the relationship between placement instability and expressed unmet need was largely based on the fact that emancipated foster youth tend to identify foster parents as important sources of information relating to independent living. We hypothesized that those foster youth who identified fewer placements were likely to have developed relationships with their caregivers that enabled the transfer of independent living skills, ultimately resulting in their expression of fewer unmet needs. We also hypothesized that placement instability may make it difficult for youth to receive formal and informal services intended to provide them with independent living skills, resulting in the more frequent expression of unmet need. We created a measure of placement instability based on the sum of foster homes and group homes in which youth had lived while in foster care ${ }^{2}$.

We were also interested in examining placement type in light of our belief that type of placement may be linked with receipt of formal and informal living services prior to emancipation. For example, Courtney, Lee \& Perez (2011) found that youth who lived in group home settings were more likely to receive formal independent living services than their counterparts in foster homes, speculating that this was a result of the contractual obligation of group home operators to provide mandatory trainings. The receipt of such independent living services may equate with fewer unmet needs. In another example, youth who live in kinship placements may have received more informal independent living skills training than their counterparts in non-kinship foster care as a result of feeling more comfortable asking their family

\footnotetext{
${ }^{2}$ Should youth have experienced more than twenty placements, they were collapsed into the "20+ category". Because of the way data were coded there is no way of distinguishing youth who had twenty placements from youth who had more than twenty placements.
} 
member how to go about different tasks. The acquisition of these skills through informal channels may be linked with less expression of unmet need at baseline. These things considered, we hypothesized that there would be significant differences in services received by placement and therefore significantly varying levels of expressed unmet need between and among different types of foster care placements. Placement type was categorized into 1) non-relative foster home,

2) kinship foster home, 3) group care, and 4) other placements including pre-adoptive homes and independent living settings.

For our logistic regression model of unmet need at wave 3 we included a measure of how many months youth had remained in care past their $18^{\text {th }}$ birthday. We hypothesized that, all else being equal, youth who remained in care longer would obtain more help making the transition to adulthood and would therefore be less likely to report unmet service needs.

\subsubsection{Receipt of Independent Living Services}

We hypothesized that youth who had received more help preparing for life after foster care would report less unmet need. We therefore included measures of 44 different kinds of help youth reported receiving prior to each interview. As noted above, youth were asked about "training you may have received to help you be ready to live on your own" at baseline and waves $2 \& 3$. We refer to these forms of help as "independent living services." The 44 questions ask about help in the areas of education ( 8 questions, alpha $=.76$, example question: "Did $\mathrm{R}$ receive study skills training?"), employment (11 questions, alpha $=.88$, example question: “Did R get help with job referral/placement?”), financial and consumer literacy (7 questions, alpha $=.89$, example question: “Was R trained to use a budget?"), housing (9 questions, alpha $=.92$, example question: "Was R trained on tenants rights and responsibilities?"), and health (9 questions, alpha 
$=.92$, example question: "Was R trained on nutritional needs?"). These questions were taken from the draft data collection form produced by a U.S. Children's Bureau workgroup charged with developing survey items for states to collect data on independent living services per the requirements of the John Chafee Foster care Independence Act of 1999 (Westat, 2001). A count variable was constructed for all services received at each of the three waves based on whether or not the youth received the type of service. For the baseline logistic regression model we used the measure of services received prior to baseline. For the model of unmet need at wave 3, we included (1) a sum of services received prior to baseline and (2) a sum of services received between baseline \& wave 2 and waves $2 \& 3$.

\subsection{Analytic Approach}

For the purposes of describing trends over time in self-reported unmet need (research questions one and two), we examined descriptive statistics pertaining to unmet need, both overall and by specific domain, at baseline through wave 3 of the Midwest Study. To examine predictors of self-reported unmet need (research questions three and four) we estimated logistic regression models that show the relationship between our explanatory variables of interest and the odds that youth will report any unmet need at baseline and wave 3 of the Midwest Study ${ }^{3}$. The baseline data are of interest because they provide information about self-reported unmet need when nearly all of the youth are still in care but are on the verge of transitioning from care. States are expected to have prepared youth for the transition from care by this point in time, and in most states (including Iowa and Wisconsin) youth must leave care at age 18. The extent of unmet

\footnotetext{
3 Data from all three waves of interviews were needed to capture the total number of independent living services youth reported having received through age 21 . Analyses of the relationship between study variables and sample attrition found that none of the predictor variables used in our analyses were associated with attrition except for gender. Males were slightly less likely than females to be retained in the sample across all three interviews.
} 
need at wave 3 is of interest because the young people in the Midwest Study were all 21 years old at that point, all had left care, and it is unlikely that much if any support was available to them from their child welfare agency after that point in time.

\section{Results}

We present here the results of our analyses of self-reported unmet need for assistance among youth making the transition to adulthood from foster care. We begin with a description of our sample. We then move to a description of trends over time in unmet need and the turn to the results of our logistic regression models of predictors of unmet need at baseline and wave 3 of the Midwest Study.

\subsection{Sample Description}

Tables 1 and 2 provide descriptive statistics describing the study sample on the measures used in our analyses. At both waves, the majority of participants (64.8\% at baseline, $61.6 \%$ at wave 3) in our sample lived in the state of Illinois. Nearly $30 \%$ of them lived in Wisconsin at baseline and the remaining 9\% lived in Iowa (at wave 3, those in Wisconsin and Iowa are aggregated to comprise $38 \%$ of the sample). At both waves, slightly over half of the sample is female (52\% at baseline, $53 \%$ at wave 3 ). At both waves, about one third of the sample is white (31\% at baseline, $33 \%$ at wave 3), slightly over half the sample is African American (57\% at baseline, $56 \%$ at wave 3 ) and the remainder of the sample is identified as a race other than white or African American (12\% at baseline, $11 \%$ at wave 3). 
Table 1. Sample Demographics \& Bivariate Analyses: Baseline

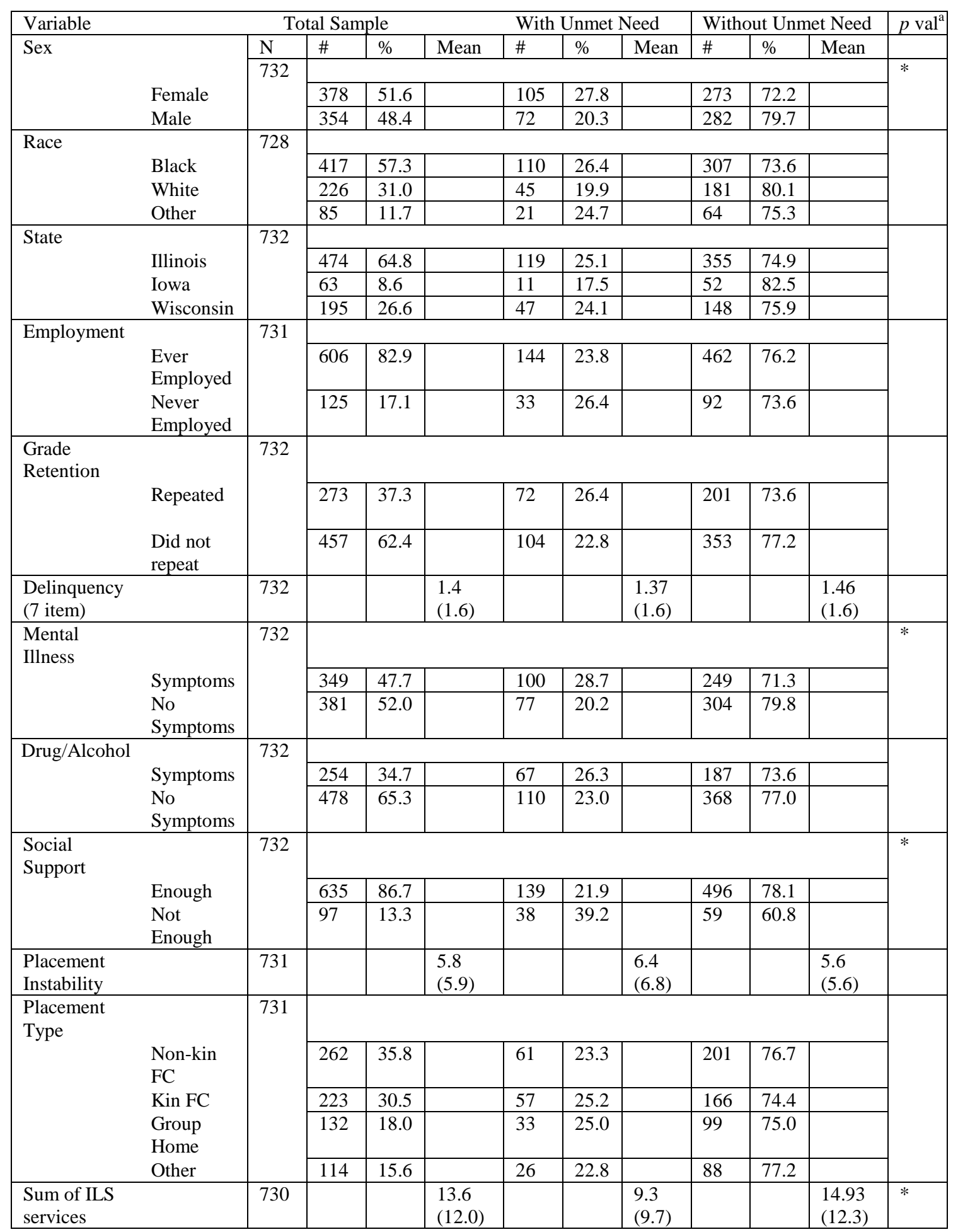

a $*: p<.05 ; * * p<.01$ 
Table 2. Sample Demographics \& Bivariate Analyses: Wave 3

\begin{tabular}{|c|c|c|c|c|c|c|c|c|c|c|c|c|}
\hline \multirow{2}{*}{\multicolumn{2}{|c|}{$\begin{array}{l}\text { Variable } \\
\text { Sex }\end{array}$}} & \multicolumn{3}{|c|}{ Total Sample } & \multicolumn{4}{|c|}{ With Unmet Need ${ }^{\mathrm{b}}$} & \multicolumn{3}{|c|}{ Without Unmet Need $^{\mathrm{b}}$} & \multirow[t]{2}{*}{$p \mathrm{val}^{2}$} \\
\hline & & $\mathrm{N}$ & $\#$ & $\%$ & Mean & $\#$ & $\%$ & Mean & $\#$ & $\%$ & Mean & \\
\hline & \multirow{3}{*}{$\begin{array}{l}\text { Female } \\
\text { Male }\end{array}$} & \multirow[t]{3}{*}{591} & & & & & & & & & & \\
\hline & & & 315 & 53.3 & & 113 & 35.9 & & 196 & 62.2 & & \\
\hline & & & 276 & 46.7 & & 99 & 35.9 & & 165 & 59.8 & & \\
\hline \multirow[t]{4}{*}{ Race } & \multirow{4}{*}{$\begin{array}{l}\text { Black } \\
\text { White } \\
\text { Other }\end{array}$} & \multirow[t]{4}{*}{588} & & & & & & & & & & \multirow[t]{4}{*}{$*$} \\
\hline & & & 328 & 55.8 & & 134 & 40.9 & & 182 & 55.5 & & \\
\hline & & & 193 & 32.8 & & 56 & 29.0 & & 131 & 67.8 & & \\
\hline & & & 67 & 11.4 & & 21 & 31.3 & & 46 & 68.7 & & \\
\hline \multirow[t]{3}{*}{ State } & \multirow{3}{*}{$\begin{array}{l}\text { Illinois } \\
\text { IA/WI }\end{array}$} & \multirow[t]{3}{*}{591} & & & & & & & & & & \multirow[t]{3}{*}{$* *$} \\
\hline & & & 364 & 61.6 & & 146 & 40.1 & & 204 & 56.0 & & \\
\hline & & & 227 & 38.4 & & 66 & 29.1 & & 157 & 69.2 & & \\
\hline \multirow[t]{3}{*}{ Employment } & \multirow{3}{*}{$\begin{array}{l}\text { Currently } \\
\text { Employed } \\
\text { Not } \\
\text { Currently } \\
\text { Employed }\end{array}$} & 589 & & & & & & & & & & \\
\hline & & & 303 & 51.3 & & 102 & 33.7 & & 192 & 63.4 & & \\
\hline & & & 286 & 48.4 & & 109 & 38.1 & & 168 & 58.7 & & \\
\hline $\begin{array}{l}\text { Delinquency } \\
\text { (6 item) }\end{array}$ & & 505 & & & $\begin{array}{l}.38 \\
(.89)\end{array}$ & & & $\begin{array}{l}.53 \\
(1.1)\end{array}$ & & & $\begin{array}{l}.32 \\
(.76)\end{array}$ & $*$ \\
\hline \multirow[t]{3}{*}{ Mental Illness } & \multirow{3}{*}{$\begin{array}{l}\text { Symptoms } \\
\text { No } \\
\text { Symptoms }\end{array}$} & 591 & & & & & & & & & & \multirow[t]{3}{*}{$* *$} \\
\hline & & & 200 & 33.8 & & 91 & 45.5 & & 104 & 52.0 & & \\
\hline & & & 391 & 66.2 & & 121 & 30.9 & & 257 & 65.7 & & \\
\hline \multirow[t]{3}{*}{ Drug/Alcohol } & \multirow{3}{*}{$\begin{array}{l}\text { Symptoms } \\
\text { No } \\
\text { Symptoms }\end{array}$} & 591 & & & & & & & & & & \\
\hline & & & 85 & 14.4 & & 37 & 43.5 & & 46 & 54.1 & & \\
\hline & & & 506 & 85.6 & & 175 & 34.6 & & 315 & 62.3 & & \\
\hline \multirow[t]{3}{*}{$\begin{array}{l}\text { Social } \\
\text { Support }\end{array}$} & \multirow{3}{*}{$\begin{array}{l}\text { Enough } \\
\text { Not } \\
\text { Enough }\end{array}$} & 590 & & & & & & & & & & \multirow[t]{3}{*}{$* *$} \\
\hline & & & 470 & 79.7 & & 151 & 32.1 & & 305 & 64.9 & & \\
\hline & & & 120 & 20.3 & & 60 & 50.0 & & 56 & 46.7 & & \\
\hline \multirow{4}{*}{$\begin{array}{l}\text { Highest } \\
\text { Grade }\end{array}$} & \multirow{4}{*}{$\begin{array}{l}\text { Less than } \\
\text { HS } \\
\text { HS or } \\
\text { GED } \\
\text { Some } \\
\text { College/2 } \\
\text { yr degree }\end{array}$} & 589 & & & & & & & & & & $*$ \\
\hline & & & 135 & 22.9 & & 53 & 39.3 & & 77 & 57.0 & & \\
\hline & & & 279 & 47.4 & & 85 & 30.4 & & 185 & 66.3 & & \\
\hline & & & 175 & 29.7 & & 72 & 41.1 & & 99 & 56.6 & & \\
\hline $\begin{array}{l}\text { Months in } \\
\text { care }>18\end{array}$ & & 591 & & & $\begin{array}{l}17.32 \\
(16.7)\end{array}$ & & & $\begin{array}{l}19.61 \\
(16.8)\end{array}$ & & & $\begin{array}{l}15.9 \\
(16.5)\end{array}$ & $*$ \\
\hline $\begin{array}{l}\text { Sum of ILS } \\
\text { services }\end{array}$ & & 591 & & & $\begin{array}{l}10.84 \\
(12.0)\end{array}$ & & & $\begin{array}{l}8.8 \\
(10.6)\end{array}$ & & & $\begin{array}{l}12.12 \\
(12.7)\end{array}$ & $* *$ \\
\hline
\end{tabular}

a $*: p<.05 ; * * p<.01$

${ }^{\mathrm{b}}$ : There were 18 missing cases in the measure of unmet need at wave 3 .

Tables 1 and 2 also provide the results of bivariate analyses conducted with all measures used in our analyses. Chi-square analyses were conducted with each measure in an effort to establish which youth were more likely to express unmet need on a bivariate level at baseline and 
at wave 3. At baseline, females were more likely to express unmet need than their male counterparts (28\% vs. $20 \%)$. Those with symptoms of PTSD and/or dysthymia were also more likely to express unmet need than those without these symptoms (28\% vs. $20 \%$ ). Alternatively, those who identified at least one adult providing social support were less likely to express unmet need than those who were unable to identify one adult providing social support (22\% vs. $39 \%$ ) and those who reported receiving more independent living services were less likely to express unmet need than those who reported receiving fewer services (those who did not express unmet need reported receiving an average of 15 services; those who did express unmet need reported receiving an average of 9 services).

At wave 3 , females and males were relatively equal in their expression of need but African American youth became more likely than White or Other youth to express unmet need ( $41 \%$ vs. $29 \%$ for White youth and $31 \%$ for Other youth). Those from Illinois were also more likely to express need than youth from the other two states (40\% vs. $29 \%$ ). These findings are correlated, as over three-quarters of youth who identified as African American at wave 3 were living in Illinois. Youth who reported mental health symptoms were more likely to report unmet need than those who did not (46\% vs. $31 \%$ ) and those who spent more time in care past age 18 were more likely to report unmet need than those who spent less time in care past age 18 (20 months vs. 16 months). Finally, similar to the baseline findings, those who identified at least one adult providing social support were less likely to express unmet need than those who were unable to identify one adult providing social support (32\% vs. 50\%) and those who reported receiving more independent living services were less likely to express unmet need than those who reported receiving fewer services (those who did not express unmet need reported receiving 
an average of 12 services since wave 2; those who did express unmet need reported receiving an average of 9 services since wave 2).

\subsection{Trends in Unmet Need}

As shown in Table 3, the percentage of youth who participated in all three waves of data collection that indicated an unmet service need in at least one domain ranged from $28 \%(\mathrm{n}=144)$ at wave 2 to $36 \%(n=185)$ at wave 3. Interestingly, the most frequent response given was "all of the above." Coders would categorize a response as "all" when a subject would state that they had an unmet need in "all" of our defined domains. At baseline, slightly over 17\% (n=87) indicated that they had an unmet need in every domain; at wave 2, nearly $10 \%(\mathrm{n}=51)$ and at wave 3 , over $11 \%(\mathrm{n}=56)$ indicated that they had unmet needs in all the domains.

Table 3

Expressions of Unmet Need: Baseline, Wave 2 and Wave 3

( $\mathrm{N}=513$ or those who participated in all 3 waves of data collection)

\begin{tabular}{|c|c|c|c|c|c|c|}
\hline & Baseline & Wave 2 & Wave 3 & W1/W2 ${ }^{a}$ & $\mathbf{W} 1 / \mathrm{W3}^{\mathrm{a}}$ & $\mathbf{W}^{2} / \mathbf{W 3}^{\mathrm{a}}$ \\
\hline Any Need & $34.5 \%$ & $27.9 \%$ & $35.5 \%$ & $* *$ & $*$ & $* *$ \\
\hline Finance & $10.3 \%$ & $7.8 \%$ & $14.0 \%$ & & & $* *$ \\
\hline Housing & $8.0 \%$ & $6.6 \%$ & $7.6 \%$ & $*$ & & $*$ \\
\hline Health & $.8 \%$ & $1.0 \%$ & $2.9 \%$ & & & \\
\hline Education & $1.8 \%$ & $2.1 \%$ & $3.7 \%$ & & & \\
\hline Employment & $1.4 \%$ & $3.1 \%$ & $6.0 \%$ & & & \\
\hline Relationships & $2.7 \%$ & $2.9 \%$ & $4.5 \%$ & & & $*$ \\
\hline $\begin{array}{l}\text { All of the } \\
\text { Above }\end{array}$ & $17.2 \%$ & $9.9 \%$ & $11.3 \%$ & $* *$ & $*$ & $* *$ \\
\hline
\end{tabular}

The other most frequently indicated domain of unmet need was finance. Youth who expressed need were most likely to feel as though their needs were not met in the area of financial preparation for independent living. This percentage reached $14 \%(n=72)$ of the sample at wave 3. Housing was also a predominant area of expressed unmet need, with up to $8 \%(\mathrm{n}=41)$ 
of the sample indicating that they did not adequately receive the services they needed pertaining to the acquisition and maintenance of permanent housing.

Basic descriptive data showed that rates of unmet need fluctuated slightly between waves: nearly 35\% $(n=180)$ expressed any unmet need at baseline, $28 \%(n=144)$ expressed any unmet need at wave 2 and nearly 36\% (n=185) expressed any unmet need at wave 3 . Bivariate analyses showed that there were significant differences in reported need in the "Any Need" category between baseline and wave $2(\mathrm{p}=.000)$, baseline and wave $3(\mathrm{p}=.033)$ and waves 2 and $3(\mathrm{p}=.000)$. There were also significant differences in expression of need $($ at $\mathrm{p}<.05$ and $\mathrm{p}<.01)$ by domain in other areas. These findings beg the question of whether some respondents were likely changing their minds, either discovering that they had not received all of the services that they required for successful independent living as they became older, or indicating that the services they received were, in fact, adequate. We were interested in evaluating the levels of reported need for the following four groups: (1) those who reported an unmet need at all three waves; (2) those who reported no unmet need at all three waves; (3) those who originally reported that their needs were met, then changed their mind in either wave 2 or wave 3 and (4) those who originally reported that they had an unmet need, then changed their mind in either wave 2 or wave 3. 


\section{Table 4}

Change in Self-Reported Unmet Service Needs Over Time ( $\mathbf{N}=513)$

\begin{tabular}{|l|l|}
\hline & $\#, \%$ \\
\hline $\begin{array}{l}\text { Expressed no unmet need at baseline, wave 2 } \\
\text { \& wave 3 }\end{array}$ & $192,37 \%$ \\
\hline $\begin{array}{l}\text { Expressed unmet need at baseline, wave 2 \& } \\
\text { wave 3 }\end{array}$ & $42,8 \%$ \\
\hline $\begin{array}{l}\text { Expressed no unmet need at baseline but did } \\
\text { express unmet need at wave 2 or wave 3 }\end{array}$ & $144,28 \%$ \\
\hline $\begin{array}{l}\text { Expressed unmet need at baseline but did not } \\
\text { express unmet need at wave 2 or wave 3 }\end{array}$ & $135,26 \%$ \\
\hline
\end{tabular}

As shown in Table 4, we discovered that those who changed their mind after baseline were about equal in number to those who did not change their mind after baseline regarding unmet need (279 changed their mind, 234 did not). 192 youths said at all three waves that all of their needs had been met. Conversely, 42 youths said at all three waves that they had unmet need. We also discovered that there were 144 youths who originally said they had no unmet need, then changed their minds with respect to a need in at least one domain at either wave 2 or 3 . There were approximately 135 youths who originally said yes, they had an unmet need, then changed their mind at either wave 2 or 3 . These findings were not significantly influenced by the fact that the majority of youth in Illinois would have still been in care at wave 2 . The percentage of those expressing any unmet need (29\%) was nearly identical between those who were in foster care at wave 2 and those who were not.

There were statistically-significant differences $(\mathrm{p}<.05)$ between youth who reported that they had received more independent living services and youth who reported that they had received fewer independent living services in the areas of finance, housing, employment, health and education. Those youth who reported receiving more independent living services were less 
likely to express that their needs were unmet at age 17 and at age 21 . These differences are demonstrated in Figures $1 \& 2$.

\section{Figure 1}

Relationship between Service Receipt and Unmet Needs at Age 17 (N=732)

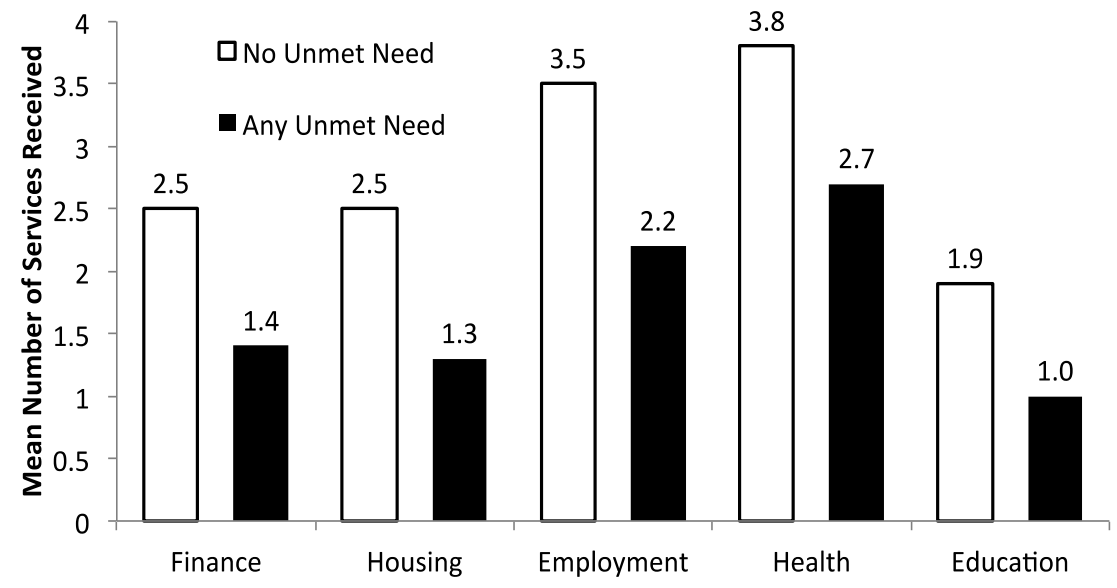

Figure 2

Relationship between Service Receipt and Unmet Needs at Age 21 (N=513)

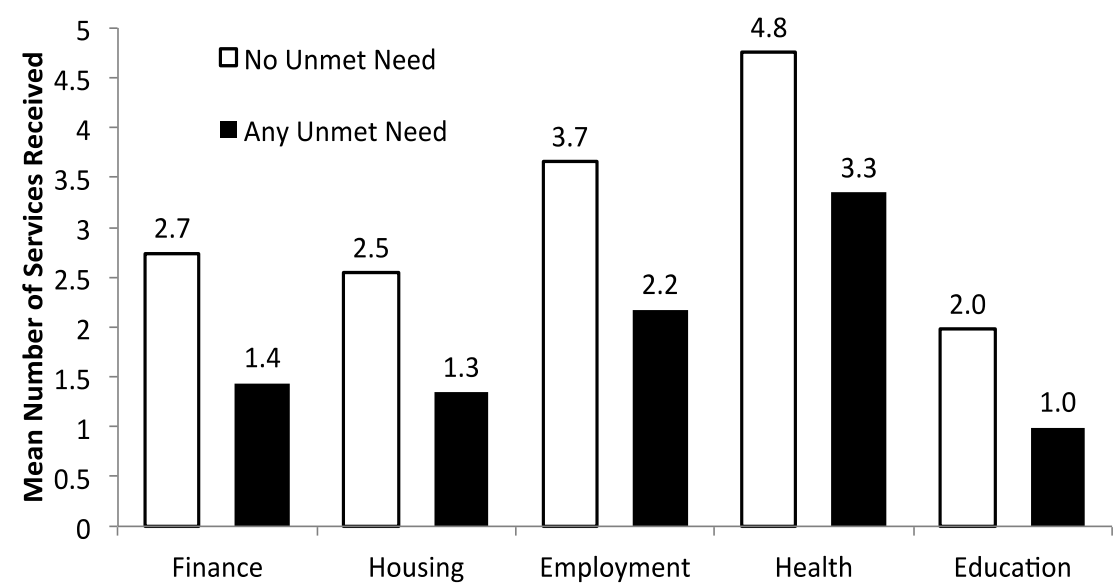

\subsection{Correlates of Unmet Need}

Table 5 shows the results of the logistic regression model for self-reported unmet needs at baseline, when the young people participating in the Midwest Study were 17-18 years old. The table shows the beta coefficients, standard errors, probability that the beta coefficient varies from 
zero by chance alone, and the odds ratio (OR) corresponding to the beta coefficient. In some cases continuous variables, indicated with an asterisk, have been standardized prior to entry in the regression model for ease of interpretation. These odds ratios measure the relationship between each variable and the likelihood that the young person reported having an unmet need for services. When subtracted from 1 and multiplied by 100, odds ratios indicate the percentage by which the estimated odds of reporting unmet need are increased or decreased by a unit change in the variable. Odds ratios significantly higher than 1 indicate an increased likelihood, odds ratio significantly lower than 1 indicate a decreased likelihood, and a variable with an odds ratio close to 1 has no effect. For categorical variables, the estimated odds ratio indicates the effect of being in one category as compared to being in the comparison group. Statistically significant odds ratios $(\mathrm{p}<.05)$ are shown in bold text. Table 5 shows that, all else being equal, having a mental health problem increases the estimated odds of reporting an unmet need by over fifty percent $(\mathrm{OR}=1.54)$. Two other variables have a statistically significant association with the estimated odds of self-reported unmet need for services at age 17-18; a one standard deviation increase in self-reported social support reduces the odds of unmet need by a factor of .57 while a one standard deviation increase in self-reported receipt of independent living services decreases those odds by a factor of .59 . 
Table 5

Logistic Regression Model Predicting Self-Reported Unmet Service Need at age 17-18 (Baseline)

\begin{tabular}{|l|r|r|r|r|}
\hline & \multicolumn{1}{|l|}{ B } & \multicolumn{1}{l|}{ S.E. } & \multicolumn{1}{l|}{ p } & \multicolumn{1}{l|}{ Odds Ratio } \\
\hline Race: Black+ & -.228 & .320 & .477 & .796 \\
\hline Race: Other+ & .070 & .300 & .817 & 1.072 \\
\hline Male & -.309 & .197 & .117 & .734 \\
\hline Ever Worked & .003 & .241 & .989 & 1.003 \\
\hline Retained in School & -.159 & .189 & .400 & .853 \\
\hline Delinquency* & -.059 & .108 & .300 & .942 \\
\hline Mental Health & $\mathbf{. 4 3 1}$ & $\mathbf{. 1 9 4}$ & $\mathbf{. 0 2 7}$ & $\mathbf{1 . 5 3 8}$ \\
\hline Drugs/Alcohol & .207 & .206 & .315 & 1.230 \\
\hline Social Support* & $\mathbf{. . 5 6 3}$ & $\mathbf{. 2 4 6}$ & $\mathbf{. 0 2 2}$ & $\mathbf{. 5 7 0}$ \\
\hline Placement Instability & .023 & .015 & .133 & 1.023 \\
\hline Placement Type: Kinship Foster & .104 & .283 & .713 & 1.110 \\
Home++ & & & & 1.189 \\
\hline Placement Type: Type: Group & .173 & .297 & .561 & 1.347 \\
Home++ & & & & $\mathbf{. 5 8 5}$ \\
\hline Placement Type: Other++ & .298 & .324 & .358 & 1.363 \\
\hline Independent Living Services* & $\mathbf{. 5 3 6}$ & $\mathbf{. 1 0 7}$ & $\mathbf{. 0 0 1}$ & 1.048 \\
\hline State: Illinois+++ & .310 & .403 & .441 & .906 \\
\hline State: Iowa+++ & .047 & .394 & & \\
\hline
\end{tabular}

+ Reference Group for race is white

++ Reference Group for placement type is non-relative foster home

+++ Reference Group for state is Wisconsin

* Variable has been standardized prior to entry in the regression model for ease of interpretation.

Table 6 shows the results of the logistic regression model for self-reported unmet needs at wave 3, when the young people participating in the Midwest Study were on average 21 years old and all had exited care. Once again, having a mental health problem, in this case in the year prior to the wave 3 interview, increased the estimated odds of having unmet service need $(\mathrm{OR}=$ 1.83). A one standard deviation increase in reported social support nearly halved the estimated odds of unmet need $(\mathrm{OR}=.55)$. Social Support also remained a significant predictor of expressed unmet need. A one standard deviation increase in social support decreased the estimated odds of unmet need by a factor of .55. While self-reported receipt of independent 
living services prior to baseline was not associated with unmet need at age 21, services reported as being received more recently during the interim between baseline and age 21 decreased the estimated odds of self-reported unmet need. Specifically, a one standard deviation increase in self-reported services received decreased the estimated odds of unmet need by a factor of 67 . Two other variables approached statistical significance; higher self-reported delinquency was associated with a non-significant increase in self-reported need $(\mathrm{p} \approx .09)$ and having remained in care longer after one's $18^{\text {th }}$ birthday was associated with a non-significant increase in need ( $p$ $\approx .06$ ).

\section{Table 6}

Logistic Regression Model Predicting Self-Reported Unmet Service Need at age 21 (Wave 3)

\begin{tabular}{|l|r|r|r|r|}
\hline & \multicolumn{1}{|l|}{ B } & \multicolumn{1}{l|}{ S.E. } & \multicolumn{1}{l|}{ p } & \multicolumn{1}{l|}{ Odds Ratio } \\
\hline Race: Black+ & -.024 & .325 & .940 & .976 \\
\hline Race: Other+ & .317 & .314 & .312 & 1.373 \\
\hline Male & .003 & .198 & .989 & 1.003 \\
\hline Currently Employed & -.100 & .202 & .621 & .905 \\
\hline $\begin{array}{l}\text { Highest Ed: High School Diploma or } \\
\text { GED++ }\end{array}$ & -.241 & .276 & .383 & .786 \\
\hline Highest Ed: Some College++ & -.348 & .233 & .135 & .705 \\
\hline Delinquency* & .167 & .100 & .095 & 1.182 \\
\hline Mental Health & $\mathbf{. 6 0 5}$ & $\mathbf{. 2 0 0}$ & $\mathbf{. 0 0 2}$ & $\mathbf{1 . 8 3 3}$ \\
\hline Drugs/Alcohol & .096 & .294 & .743 & 1.101 \\
\hline Social Support* & $\mathbf{. . 5 8 9}$ & $\mathbf{. 2 3 0}$ & $\mathbf{. 0 0 9}$ & $\mathbf{. 5 5 0}$ \\
\hline Months in Care > 18 years old & .275 & .148 & .062 & 1.317 \\
\hline State: Living in WI or IA+++ & .008 & .285 & .976 & 1.009 \\
\hline $\begin{array}{l}\text { Independent Living Services } \\
\text { Received Prior to Baseline* }\end{array}$ & -.039 & .099 & .696 & .962 \\
\hline $\begin{array}{l}\text { Independent Living Services } \\
\text { Received After Baseline and Prior } \\
\text { to Wave 3* }\end{array}$ & $\mathbf{. . 3 9 5}$ & $\mathbf{. 1 0 9}$ & $\mathbf{. 0 0 1}$ & $\mathbf{. 6 7 4}$ \\
\hline Refond & & & & \\
\hline
\end{tabular}

+Reference Group for race is white

++ Reference Group for highest education is some high school (no diploma or GED)

* Variable has been standardized prior to entry in the regression model for ease of interpretation. 


\section{Discussion}

We began this study with four central research questions relating to the reported unmet need of youth aging out of the foster care system. The first concerned the percentage of those youth who expressed unmet need. It was not surprising that over one quarter of our sample reported that the agency had not met all of their needs pertaining to independent living, and it was also not surprising that unmet needs most frequently fell in the domains of finance and housing (two of the most frequent categories of need in the existing literature). These findings seem to point to the importance of quality independent living service provision in areas emancipating youths have identified as important. Foster care agencies should periodically survey emancipating teens prior to their departure from care, inquiring about the services they have received, and asking if there are areas of service for which they feel a need. Such agencies would need to keep in mind, however, that emancipating youth may not yet be aware of the challenges they will encounter in the years following emancipation.

The frequency with which the young people expressed that they had unmet service needs in "all" of the domains they were asked about is troubling. As mentioned, this could be the result of the youths short-handedly replying "everything" or a response similar in nature when asked if there were services they needed that were not provided by the agency. It could also reflect general dissatisfaction with and/or disappointment about their foster care experience.

Nevertheless, the clear sense that comes from a review of the short answers recorded by the interviewers is that many of the young people, after being asked a long list of questions about various kinds of help that their agency had a statutory obligation to provide, seemed to believe that they had in fact received very little help in the service domains they were asked about. 
Our second question concerned changes over time in reported unmet need. We discovered that a sizeable percentage of the respondents changed their responses over time; some who had described unmet service needs at baseline reported no unmet needs later on, whereas others who reported having received the help they needed before the age of 18 later reported that they perceived a need for services they had not received. For those youths who reported no unmet need at baseline and changed their mind at either wave 2 or 3 , we believe this might have been due to the fact that these youths encountered challenges associated with independent living that they had not anticipated and did not have the skill set to successfully navigate, despite whatever independent living skills they had acquired in foster care or after foster care. We believe that those youths who reported unmet need at baseline but reported no unmet need later on may have had their needs met either in the foster care setting (for those youths who aged out after the age of 18) or through after-care programming. They may also have their needs met by a variety of institutions other than their child welfare agency or through informal social support. The changing perceptions of need reported by these youths help illustrate how the transition to adulthood is an ongoing process with ups and downs for many young people, providing support for ongoing provision of independent living services through at least age 21, consistent with the provisions of the Chafee Program.

Our third question sought to identify youth characteristics associated with self-reported unmet service need. A few factors were consistently associated with greater perceptions of unmet need both at the age of majority, when nearly all of the youth were still in care, and at age 21 , when all of them had left care. Youth with mental health problems, specifically symptoms of depression or PTSD, were much more likely than those without such problems to report unmet need. The underlying meaning of this relationship is unclear. Perhaps young people with these 
kinds of mental health problems have generally heightened anxiety about the transition to independence and as a result perceive a range of unmet service needs. Alternatively, their mental health problems may in fact impair their ability to make full use of services that are available to them, leaving them feeling unprepared. In either case, our findings suggest that special attention be paid to youth approaching the transition to adulthood from care with mental health problems to ensure that they are accessing services that are appropriate given their level of functioning.

All else being equal, youths who reported greater levels of social support were much less likely to report having unmet service needs. We believe that this is likely a result of these youths feeling generally more secure about their ability to navigate the transition to adulthood because of the support they believe they have, thus leading to a reduced perception of the need for independent living services to assist them with the transition. Also, to the extent that our questions about the kinds of help youths received described important services imperfectly, the observed relationship between social support and lower perceived unmet service need may reflect the fact that young people who are relatively more able to acquire social support are also better able to acquire the social services they desire.

Two variables that approached statistical significance in our regression model predicting unmet service need at age 21 deserve mention. That youths who reported engaging in delinquent behavior may also be more likely to report unmet need calls attention to youth in care with externalizing behavior problems. Indeed, a latent class analysis of transition outcomes for Midwest Study participants found that a subgroup of "troubled and troubling" young people with a history of externalizing behavior problems was the group most likely to report during the baseline interview feeling unprepared for the transition to adulthood (Courtney, Hook, \& Lee, 
2012). We also found that youth who remained in care longer past age 18 may perceive greater unmet service need. This finding may seem counterintuitive, since remaining in care longer should be associated with greater support during the transition. However, it is important to keep in mind that the regression model controls for self-reported receipt of independent living services and prior research has shown that remaining in care is strongly associated with greater receipt of services (Courtney, Lee, \& Perez, 2011). This finding may simply be a function of selection; all else being equal, youth who feel more prepared may be more likely to leave care early, leaving those who feel less prepared behind. Alternatively, perhaps youth still in care are in more frequent contact with professionals who remind them of the need to be better prepared for independence.

Lastly, our fourth question concerned whether greater self-reported receipt of independent living services was associated with a reduced likelihood of reported unmet need. Encouragingly, those youths who reported receiving more independent living services were significantly less likely to report unmet need. While our regression analyses did not distinguish between different types of independent living services and distinct categories of unmet need, preliminary descriptive analyses showed that youth who reported receiving more services in a specific area were less likely to later report unmet need in that area. This finding applied to every one of the major service domains identified through the coding of youths' responses. These findings suggest that increasing receipt of independent living skills translates into feelings of greater preparedness. While there remains a great need to develop evidence of the effectiveness of independent living services, our findings suggest that at least youth perceive a need for such assistance. 


\section{Study Limitations}

This study's findings should be interpreted in the context of study limitations. First, youth participating in the baseline interview were asked to recall the independent living training they received while in care but were not asked to recall who provided this training. Training could have been provided by any number of parties including an agency representative, a friend, a foster parent/foster family member or a biological parent/family member. It could have been provided in a formal manner (i.e. a required program provided by a foster care agency) or in an informal manner (i.e. at the kitchen table of a foster home over dinner). It would have been helpful to know how the independent living skills acquired by youth in this sample were acquired, particularly in light of the fact that these youth are entitled to services such as these under the Chafee Act.

Second, this study is based on recall and self-report. Our findings are based on the services youth remember receiving as opposed to the services agencies have documented providing (these two things may differ). Youth may not remember the full content of a particular training that was offered to them, particularly if that training was offered a year or more before they were asked questions relating to unmet need at the baseline interview (this has been a critique of foster care agencies in the past; Iglehart \& Becerra, 2002). It is possible that the youth in this sample received more independent living services than they remembered and/or reported.

Third, because the question about unmet service needs was an open-ended question, at all

three waves of data collection youth had the opportunity to effectively respond "all of the above" when asked about unmet need. Interviewers would generally enter the text "all of the above" or "all of the service areas" as a youth's response to the open-ended question if a youths' response implied that the youth had at least one unmet service need in all of the service domains that 
youth had been asked about. It is possible that youth who felt as though their needs were not met in most of the domains simply responded that they had unmet needs across all domains rather than being more specific. This may have skewed the findings away from the domain-specific needs and towards the "all of the above" category.

Lastly, interrater reliability (IR) was fairly high for all domains included in this study except the relationship domain: the IR score for the relationships domain ranged between $32 \%$ and $58 \%$ across interview waves. Our findings regarding unmet need for services intended to improve youths' relationships should be regarded with particular caution.

\section{Future Research}

There are a number of ways in which future scholarship could build upon these findings. Many of the youth who participated in the Midwest Study appeared to feel as though they had received the independent living skills they needed to live on their own after emancipation; $37 \%$ of the youth did not report an unmet service need at any wave of data collection. Future studies could explore how these youth acquired these independent living skills and if training (informal and/or formal) took place close to the age of emancipation. Youth in an alternate study emphasized that ILPs would become more useful if they were offered closer to the time of emancipation (Iglehart \& Becerra, 2002).

Further, it remains unclear whether independent living skills are most effectively acquired in formal or informal settings. Youth in a number of studies stated that the foster home was an ideal location for the acquisition of independent living skills, citing trusted foster parents as ideal trainers (Mares, 2010; McMillen et al, 1997; Geenen \& Powers, 2007; Scannapieco et al, 2007). Such youth tend to believe that foster parents could demonstrate both hard and soft 
independent living skills in day-to-day life, providing informal training through modeling and explanation. Youth in another study state that long-term foster care caseworkers might be the most appropriate party to provide soft skills training (Iglehart \& Becerra, 2002). Either or both of these possibilities may be true. There is great utility in learning more about effective service provision in an effort to replicate successful trainings and wisely allocate resources.

There is also great utility in identifying and improving unsuccessful services: many foster care agencies are providing ILPs that have not been formally evaluated. More of these evaluations need to be taking place. Further, improvements need to be taking place when evaluations reveal that there is little evidence in support of ILP effectiveness (Montgomery, Donkoh, \& Underhill, 2006; Courtney, Zinn, Johnson, \& Malm, 2011; Courtney et al, 2008). A sizeable percentage of foster youth continue to fail at many independent living tasks despite participating in agency-provided ILPs; the field has a responsibility to consistently provide youth with independent living skills, evaluate the services it provides for that purpose, and enhance the services that are not proven effective.

Youth in this study expressed a particular need for training in the area of finance: between $10.3 \%$ and $14 \%$ identified an unmet need in the finance domain between baseline and wave 3. It is likely that these youth felt that they did not have the financial skills required of them after emancipation. Some youth may have known their training was inadequate prior to emancipation. Others may have discovered their training was inadequate after being presented with a financial challenge they were ill equipped to navigate. Qualitative studies are needed to better understand the skills and/or information that would be particularly useful or relevant for youth emancipating today. What are the financial tasks for which emancipating youth feel least prepared? What type of financial training would be most useful for youth prior to emancipation? 
What training format would be most useful, comfortable and/or effective? When would this training ideally take place? This kind of data could make existing training initiatives more relevant and effective, ultimately preparing emancipating foster youth for greater financial success.

Along these same lines, it's important to understand how reported unmet needs correlate with subsequent outcomes during early adulthood. It would logically follow that youth who report unmet need in a particular domain may have encountered a problem in that domain. For example, a subject who reported unmet need in the domain of housing at wave 3 may have made this report after failing to secure public housing and becoming homeless. Future research should explore the short and long term consequences of reporting unmet needs in various domains, particularly the domains discussed in this paper: finance, housing, health, education, employment and relationships.

We also discovered that youth with symptoms of depression and/or PTSD were more likely to report unmet needs than their counterparts. It is not clear to us why this is the case, despite the hypothesis that these youths may have greater anxiety about emancipating and/or may have impaired ability to take advantage of services offered to them. Future research could further explore the relationships between and among the experience of mental illness, the acquisition of independent living skills and subsequent challenges associated with independent living in this population of youth. They may require trainings that differ in content, timing and/or location.

Finally, the data in this study were collected between 2003 and 2007. The youth in our study may have reported greater unmet need than youth emancipating from foster care today after the passage of the Fostering Connections Act and after states have begun to come into 
greater compliance with the requirements under the Chafee Act. It is important to know whether states have implemented more effective ILS training since the collection of these data and if the ILS acquisition of current emancipating foster youth has increased over time. Ideally, the foster youth who are preparing to emancipate from care today feel more prepared for independent life as states extend the age of emancipation and increase their commitment to deliver high quality independent living services.

\section{Acknowledgements}

This research was made possible by the state child welfare agencies in Illinois, Iowa and Wisconsin, the Bill and Melinda Gates Foundation, the William T. Grant Foundation, the Stuart Foundation, the Walter S. Johnson Foundation, and Casey Family Programs. 


\section{References}

Barth, R. (1990) On their own: The experiences of youth after foster care. Child and Adolescent Social Work, 7(5), 419-440.

Berzin, S. C., Rhodes, A. M., \& Curtis, M. A. (2011). Housing experiences of former foster youth: How do they fare in comparison to other youth?. Children and Youth Services Review, 33(11), 2119-2126.

Courtney, M. E. (2009). The difficult transition to adulthood for foster youth in the US: Implications for the state as corporate parent. Social Policy Report, 23(1), 3-18.

Courtney, M. E., Dworsky, A., Brown, A., Cary, C., Love, K., \& Vorhies, V. (2011). Midwest evaluation of the adult functioning of former foster youth: Outcomes at Age 26. Chicago: Chapin Hall at the University of Chicago.

Courtney, M. E., Hook, J. L., \& Lee, J. S. (2012): Distinct subgroups of former foster youth during young adulthood: Implications for policy and practice. Child Care in Practice, 18(4), 409-418.

Courtney, M. E., Lee, J., \& Perez, A. (2011). Receipt of help acquiring life skills and predictors of help receipt among current and former foster youth. Children and Youth Services Review, 33: 2442-2451.Courtney, Lee \& Perez (2011)

Courtney, M., Zinn, A., Johnson, H., and Malm, K. (2011). Evaluation of the Massachusetts Adolescent Outreach Program for Youths in Intensive Foster Care: Final Report. OPRE Report \#2011-14. Washington, DC: Office of Planning, Research and Evaluation, Administration for Children and Families, U.S. Department of Health and Human Services.

Courtney, M. E., Zinn, A., Zielewski, E. H., Bess, R. J., Malm, K. E., Stagner, M., \& Pergamit, M. (2008). Evaluation of the Life Skills Training Program: Los Angeles County. Washington, DC: U.S. Department of Health and Human Services, Administration for Children and Families.

Courtney, M. E., Terao, S., \& Bost, N. (2004). Midwest evaluation of the adult functioning of former foster youth: Conditions of youth preparing to leave state care. Chapin Hall Center for Children at the University of Chicago..

Dworsky, A. L., \& Havlicek, J. (2009). Review of state policies and programs to support young people transitioning out of foster care. Chapin Hall Center for Children at the University of Chicago.

Havlicek, J. (2011). Lives in motion: A review of former foster youth in the context of their experiences in the child welfare system. Children and youth services review, 
33(7), 1090-1100.

Iglehart, A.P and Becerra, R.M. (2002) Hispanic and African American youth:

Life after foster care emancipation. Journal of Ethnic and Cultural

Diversity in Social Work, 11(1), 79-107.

Geenen, S. \& Powers, L.E. (2007) Tomorrow is another problem: The experiences of youth in foster care during their transition into adulthood. Children and Youth Services Review, 29, 1085-1101.

Mares, A. S. (2010). An assessment of independent living needs among emancipating foster youth. Child and Adolescent Social Work Journal, 27(1), 79-96.

McMillen, J.C., Rideout, G.B., Fisher, R. H. \& Tucker, J. (1997) IndependentLiving Services: The Views of Former Foster Youth. Families in Society: The Journal of Contemporary Human Services, 78, 471-479.

Montgomery, P., Donkoh, C, and Underhill, K. (2006). Independent living programs for young people leaving the care system: The state of the evidence. Children and Youth Services Review, 28(12):1435-48.

Pecora. P. J., Williams J., Kessler, R.C., Downs, A.C., O’Brien, K., Hiripi, E. et al (2003). Assessing the effects of foster care: early results from the Casey National Alumni Study. Casey Family Programs, Seattle

Scannapieco, M., Connell-Carrick, K. \& Painter, K. (2007) In their own words: Challenges facing youth aging out of foster care. Child \& Adolescent Social Work, 24, 423-435.

Udry, J.. (2003). The National Longitudinal Study of Adolescent Health (Add Health), Waves I \& II, 1994-1996; Wave III, 2001-2002. Chapel Hill, NC: Carolina Population Center, University of North Carolina at Chapel Hill.

US Government Accountability Office (2004) HHS Actions Could Improve Coordination of Services and Monitoring of States' Independent Living Programs [GAO-05-25]. Washington, DC: Author.

Westat (2001) Notes taken at the meeting of the U.S. Children's Bureau Workgroup on measuring Independent Living Services. Unpublished.

World Health Organization (1998). The Composite International Diagnostic Interview (CIDI). Geneva, Switzerland. 